\title{
Scripts of Sexual Desire and Danger in US and Dutch Teen Girl Magazines: A Cross-National Content Analysis
}

\author{
Suchi P. Joshi • Jochen Peter • Patti M. Valkenburg
}

Published online: 14 February 2011

(C) The Author(s) 2011. This article is published with open access at Springerlink.com

\begin{abstract}
The aim of this comparative quantitative content analysis was to investigate how US and Dutch teen girl magazines cover sexual desire (i.e., sexual wanting, and pleasure) and sexual danger (i.e., sexual risk, and negative physical/health consequences of sex). Relying on the sexual scripts framework and Hofstede's cultural dimension of masculinity/femininity, we examined (a) how the coverage varied for boys and girls, (b) how it differed between the United States and the Netherlands, and (c) how gender differences varied by country. The sample comprised 627 sex-related feature stories from all 2006-2008 issues of three US (i.e., Seventeen, CosmoGirl! United States edition, and Teen) and three Dutch teen girl magazines (i.e., Fancy, CosmoGirl! Netherlands edition, and Girlz!). Overall, sexual wanting occurred more frequently in the US magazines than in the Dutch magazines. In the US coverage, boys' sexual wanting received more attention than girls' sexual wanting, whereas in the Dutch coverage sexual wanting was depicted equally often for boys and girls. The depiction of sexual pleasure did not vary by gender in either country, but was generally more visible in the Dutch magazines than in the US magazines. Sexual risks and the negative consequences of sex were associated with girls more than with boys, and were primarily depicted in the US magazines rather than in the Dutch magazines.
\end{abstract}

Keywords Adolescents · Media - Cultural differences . Cross-national research $\cdot$ Sexuality

\footnotetext{
S. P. Joshi $(\triangle) \cdot$ J. Peter $\cdot$ P. M. Valkenburg

Amsterdam School of Communication Research ASCoR, University of Amsterdam,

Kloveniersburgwal 48,

1012 CX Amsterdam, The Netherlands

e-mail: s.p.joshi@uva.nl
}

\section{Introduction}

The media are consistently acknowledged as an important influencer of adolescents' sexual socialization (APA 2007; Brown et al. 2006; Epstein and Ward 2008; Peter and Valkenburg 2007; Prinstein et al. 2003; Ward 2003). Of the media adolescents refer to as sources of information about sex and sexuality, teen magazines are particularly important (Carpenter 1998; Garner et al. 1998; Ward 2003) because they offer a variety of easily accessible information about sex. As a result, various content analyses of topics related to sex and sexuality in popular teen and women's magazines have been conducted in numerous countries, such as the United States, Germany, New Zealand, Australia, and the Netherlands (Carpenter 1998, 2001; Farvid and Braun 2006; Firminger 2006; Garner et al. 1998; Hust et al. 2008; Schlenker et al. 1998; Stankiewicz and Rosselli 2008; Willemsen 1998). Two of the most popular themes that past studies have identified in women's and teen magazines are sexual desire and the dangers associated with sex (for a review, see Ward 2003). According to Tolman (2000), sexual desire refers to strong, embodied, passionate feelings of sexual wanting, as well as knowing, listening to, and taking into account one's own bodily sexual feelings through pleasure. The notion of sexual danger is conveyed through sexual risks and negative physical/health consequences of sex, such as men's aggression, women's sexual victimization, unwanted pregnancy, sexually transmitted diseases (STDs), and rape (e.g., Garner et al. 1998; Johnson et al. 1999; Kim and Ward 2004).

Past research has studied the gender-specific nature of sexual desire and danger through content analyses of teen magazines in the US, New Zealand, and Australia, and through interviews with parents and teenagers in the US 
and the Netherlands (e.g., Carpenter 1998; Farvid and Braun 2006; Schalet 2000, 2004; Tolman 2002). However, no research to date has investigated, in one single study, the extent to which the coverage of desire and danger in teen girl magazines is both gender- and culture-specific. This lack of research is striking because it is well-documented that the experience of sex and sexuality varies both by gender (e.g., Schlenker et al. 1998; Taylor 2005; Willemsen 1998) and by country (e.g., Ford and Beach 1951; Frayser 1985; Gregersen 1986; Hofstede 1998a). Therefore, it is the main goal of the present study to investigate, with a crossnational comparative quantitative content analysis, how the coverage of sexual desire and danger in teen girl magazines may differ between countries and by gender. By comparing the coverage in the United States and the Netherlands, two countries that differ in their approach to adolescent sexuality, this study may help put earlier, single-culture research into perspective. Specifically, our comparative approach may help us understand whether current conclusions about teen magazine coverage may be culturally biased.

\section{Gender Differences for Desire and Danger}

Many previous content analyses have used the sexual scripts framework to investigate the representation of adolescent sexuality in teen magazines and other media (e.g., Carpenter 1998, 2001; Kim and Ward 2004). The sexual scripts framework posits that sexual matters are not universal, but are shaped by sociocultural processes. Sociocultural processes determine what is considered sexual and how individuals behave sexually (Simon and Gagnon 1984). As a result, what is considered sexual for adolescents may vary according to social groups (e.g., gender) and/or cultures (e.g., countries). The sexual scripts framework thus provides the conceptual basis for expecting the depiction of desire and danger in teen magazines to differ by gender and country.

The sexual scripts framework distinguishes between three types of scripts: cultural scripts, which correspond to the collective level of society; interpersonal scripts, which relate to small-group interactions; and intrapsychic scripts, which are associated with individual dimensions of society (Bowleg et al. 2004; Hynie et al. 1998). Because teen magazines exist at the collective level of society, they create and maintain cultural scripts (Carpenter 2001) by informing adolescents about when, where, with whom, why, and how to engage in sexual interactions (Laumann et al. 1994). One of the most important cultural scripts, especially in the US, is the Heterosexual Script, which outlines romantic encounters and sexual interactions for boys and girls (e.g., Hyde and Oliver 1993; Kim et al. 2007; Tolman 2002). Two crucial parts of the Heterosexual Script are sexual desire and danger.

Studies from the US, Australia, and New Zealand indicate that sexual desire in the Heterosexual Script has been framed with a strong emphasis on men's and boys' sexual ability and performance (Farvid and Braun 2006; Kilmartin 1999). Men are positioned as actively pursuing sexual relationships, guided by their sexual wants, and treating women as sexual objects (e.g., Diamond 2005; Fine 1988; Lerum and Dworkin 2009). In contrast, women's sexuality is typically portrayed as passive, with women not prioritizing their own sexual wants (e.g., Clarke and Hatfield 1989; McCormick 1979; McCormick et al. 1984; Tolman 1994, 2002). This is also true for girls' sexuality. US-based research has shown that girls' experience of sexual wants and pleasure is often considered deviant behavior (Tolman 1994, 2002).

Within research on sexual desire, pleasure is an important concept because it is inherent to experiencing, and acting out, one's own sexual desire (Tolman 2002). Consequently, researchers have increasingly paid attention to the experience of pleasure in sexual relationships (Kim and Ward 2004; Tolman 2002; Walsh-Childers et al. 2002). For example, in-depth interviews with US teenage girls have revealed that the absence of pleasure during sex is normal, and the experience of pleasure is a problem (Tolman 2002). Moreover, Australian girls attested to faking orgasms regularly to appease their partners (Roberts et al. 1995), while acknowledging the importance of their male partner experiencing pleasure. These findings echo what Michelle Fine (1988) calls "the missing discourse of desire," which highlights that dominant notions of adolescent sexuality often avoid girls' sexual wants and pleasure (Tolman 2002).

Content analyses of women's magazines on sexual desire have accordingly revealed an emphasis on men's sexuality. For example, an analysis of six consecutive issues of the Australian edition of Cosmopolitan and the New Zealand edition of Cleo has shown that men's pleasure during sex was prioritized (Epstein and Ward 2008; Farvid and Braun 2006). This prioritization of men's sexual pleasure is often linked to the lack of women's sexual desire. As a content analysis from the US has shown, young women are taught by magazines to subordinate their own interests (Kim and Ward 2004).

Sexual danger usually arises within the Heterosexual Script through the "male sexual drive" (Hollway 1989). This notion implies that when the male sexual drive takes precedence, men's sexuality becomes uncontrollable, and dangerous situations can occur for women and girls (Kim et al. 2007). In US magazines, women are positioned simultaneously as sex objects and as victims of men's uncontrollable sexual urges (Stankiewicz and Rosselli 
2008). Men do not appear to be as endangered as women, creating a double-standard within US magazines, which is consistent with stereotypical and traditional gender roles (Taylor 2005).

In the discussion of sexual danger, the risks and negative consequences of sex play a central role. It is therefore important to note gender differences for these risks and negative consequences of sex. For example, content analyses of US teen girl magazines have revealed that STDs are portrayed as a sexual risk mainly for girls, even though both boys and girls are equally susceptible to contracting diseases (Carpenter 1998; Hust et al. 2008; Stankiewicz and Rosselli 2008). Moreover, US magazines stress the negative consequences of sex from a women's point of view (Hust et al. 2008). As Carpenter (2001) found in her content analysis of US and German teen magazines, sex is treated as something physically painful for girls, for instance by focusing on the negative physical aspects of virginity loss. In addition, unwanted pregnancies are portrayed as a negative consequence of women's sexuality (Hust et al. 2008). Boys, in contrast, are generally not depicted as experiencing or being responsible for the negative consequences of sex (Kim et al. 2007; Kunkel et al. 2005).

\section{Country Differences for Desire and Danger}

The logic of cross-national comparative research requires that, when little is known about a particular subject, similar countries be chosen (e.g., Mackie and Marsh 1995). Generally, if differences between similar countries occur, they can only logically result from characteristics in which the countries differ. Thus, when little is known about a subject, and differences occur between dissimilar countries, more potential explanations exist than when differences occur between similar countries.

As outlined above, we know little about how, in a crossnational comparative perspective, teen girl magazines cover the topics of desire and danger. Consequently, when the coverage of desire and danger is compared, two similar countries should be chosen. The US and the Netherlands are two countries similar in terms of wealth, as well as education standards, and are democratically governed, highly developed nations (Schalet 2000). Moreover, in terms of more abstract cultural differences outlined in Hofstede's (2001) five dimensions of national culture, the US and the Netherlands score closely on four of the five dimensions (i.e., individualism vs. collectivism; uncertainty avoidance; power distance; and long-term vs. short-term orientation). However, the US and the Netherlands differ in terms of the masculinity/femininity dimension, with the US being a rather masculine society and the Netherlands being a rather feminine society (Hofstede 1998b, 2001).
In a masculine society, men are supposed to be "assertive, tough, and focused on material success; women are supposed to be more modest, tender, and concerned with the quality of life" (Hofstede 1998a, p. 6). Conversely, in a feminine society, "both men and women are supposed to be modest, tender, and concerned with the quality of life" (Hofstede 1998a, pp. 6-7). Because the masculinity/ femininity dimension is related to the definition of gender roles and to the cultural construction of (adolescent) sexuality (Hofstede 1998b), two countries that differ in this dimension, such as the US and the Netherlands, offer adequate comparison units for the purpose of this study.

In an attempt to categorize different sexual norms and behaviors along the masculinity/femininity dimension, Hofstede (1998b) has suggested that masculine and feminine societies differ, amongst other things, in the moral values attached to sex and how sex is experienced. Masculine societies often hold moralistic attitudes toward sexuality and associate sex with guilt and negative outcomes rather than with pleasure and positive outcomes. Conversely, feminine societies approach sexuality in a matter-of-fact way and highlight the enjoyment and positive experiences of sex. For example, conservative populations within the US often emphasize sex as something a man and woman should experience within a marriage (Luker 2006). Moreover, sex before marriage and/or promiscuity is frequently discouraged by emphasizing the dangers associated with sex. Sex is often portrayed as a risky or diseaseridden activity (Luker 2006; Schalet 2000). This moralistic approach to sex and the emphasis on danger also applies to how adolescent sexuality is approached in the US. The risks of sex are often used in sex education programs as a reason not to have sex or to remain abstinent (Pinkleton et al. 2008). Similarly, US parents consider teen sexuality to be disruptive and emphasize the negative consequences of sex (Carpenter 2001; Herzog 2008) by drawing comparisons between teen sex and drug use, excessive drinking, and vandalism (Luker 2006; Schalet 2000).

In the Netherlands, by contrast, sex is largely approached as a normal part of life, which holds true for adolescents as well (Schalet 2000). Dutch parents do not usually view teenage sex as dangerous. Although teenagers are educated and made aware of the risks associated with sex, the negative consequences are rarely used as a reason not to have sex. Moreover, sexual maturation does not tend to elicit fear among teens, parents, healthcare providers, and policy-makers in the Netherlands (Schalet 2000). Dutch adults tend to believe that adolescents have their own sexual desires and are able to express them by engaging in responsible sex, usually within loving, committed relationships (Schalet 2000).

Because teen girl magazines reflect cultural differences in how adolescent sexuality is approached (Carpenter 
2001), the differences between masculine and feminine societies may also affect how magazines cover sexual desire and danger. As a result, we expect adolescents' sexual desire to be portrayed more often in the Dutch teen girl magazines than in the US coverage. In contrast, sexuality will more often be associated with danger in the US teen girl magazines than in the Dutch magazines.

\section{Gender Differences for Desire and Danger by Country}

As a cultural script, the Heterosexual Script may differ by country. Consequently, if the coverage in teen girl magazines reflects the Heterosexual Script, then the expected gender differences in the depiction of desire and danger may further vary between countries. Technically speaking, gender and country, as predictors of differences in the coverage, may interact with each other.

Hofstede's (1998a, 2001) cultural dimension of masculinity/femininity predicts gender differences to be smaller in feminine societies than in masculine societies. Accordingly, feminine societies have been shown to distinguish between male and female sexual roles less strongly than masculine societies (Hofstede 1998b). This may also apply to adolescent sexuality. Both Dutch parents and teenagers consider sexuality and sexual urges to be a normal part of adolescence, regardless of gender (Schalet $2000,2004)$. In fact, both teenage girls and boys in the Netherlands consider sex to be fun and fulfilling, and hardly think of sex as something scary or dangerous (de Graaf et al. 2005). However, in the US, boys' sexuality and desire is encouraged and girls' sexuality and desire is discouraged - unless it benefits the boys involved (Stibbe 2004; Taylor 2005).

US-based content analyses have noticed this gender disparity within teen magazines (e.g., Durham 1998). Sexual activity is more acceptable for US boys than for US girls. Also, the risks and negative consequences of sex are hardly stressed for US boys, whereas they are prominent reasons for why US girls should not have sex (Martin 1996). Thus, in a feminine country such as the Netherlands, we expect that teen girl magazines may not depict stark differences between boys' and girls' sexual desire and danger. In contrast, teen girl magazines in a masculine country such as the US may depict greater gender disparities for sexual desire and danger.

\section{The Present Study}

Through a quantitative content analysis, this study investigates the three most popular teen girl magazines in the United States and the Netherlands. We used general linear models and logistic regressions to analyze how the coverage of sexual desire and danger: (a) varies for girls and boys, (b) differs between the United States and Netherlands, and (c) how gender differences vary by each country. Because adolescent sexuality is typically gendered (e.g., Epstein and Ward 2008; Diamond 2005; Lerum and Dworkin 2009; Taylor 2005), we hypothesize:

H1a: Sexual desire (i.e., sexual wanting, and pleasure) is more often portrayed for boys than for girls in teen girl magazines.

H1b: Sexual danger (i.e., sexual risk, and negative physical/health consequences of sex) is more often portrayed for girls than for boys in teen girl magazines

Adolescent sexuality is approached differently in masculine countries, such as the US, and feminine countries, such as the Netherlands, in terms of the moral values attached to sex and how sex is experienced (Hofstede 1998b). Thus, we expect that the coverage of sexual desire and danger will also differ between the two countries. Specifically, we hypothesize:

H2a: Sexual desire (i.e., sexual wanting, and pleasure) is more often portrayed in Dutch teen girl magazines than in US teen girl magazines.

H2b: Sexual danger (i.e., sexual risk, and negative physical/health consequences of sex) is more often portrayed in US teen girl magazines than in Dutch teen girl magazines.

Finally, we anticipate that gender differences in the coverage of sexual desire and danger may depend on whether a country is a masculine society, such as the US, or a feminine society, such as the Netherlands. Therefore, we hypothesize:

H3a: A greater gender difference for sexual desire (i.e., sexual wanting, and pleasure) is depicted in US teen girl magazines than in Dutch teen girl magazines (i.e., both Dutch and US boys are portrayed as experiencing more sexual desire than girls, but the difference in the portrayal of sexual desire between boys and girls will be greater in the US than in the Netherlands).

$\mathrm{H} 3 \mathrm{~b}$ : A greater gender difference for sexual danger (i.e., sexual risk, and negative physical/health consequences of sex) is depicted in US teen girl magazines than in Dutch teen girl magazines (i.e., both Dutch and US girls are portrayed as experiencing more sexual danger than boys, but the difference in the portrayal of sexual danger between girls and boys will be greater in the US than in the Netherlands). 


\section{Method}

Sample

We conducted a quantitative content analysis of the US teen girl magazines Seventeen, CosmoGirl! (United States edition), and Teen, as well as the Dutch teen girl magazines Fancy, CosmoGirl! (Netherlands edition), and Girlz!. These magazines were chosen because they are the most popular and widely read teen girl magazines in the US and the Netherlands, and thus may serve as a point of orientation for other teen girl magazines in the two countries (Carpenter 1998; Carpenter 2001). We opted for magazines from the years 2006, 2007, and 2008 because we wanted to obtain a comprehensive picture of the current depictions of sexual desire and danger in teen girl magazines. At the time of data collection, 2008 was the last full-year publication available for each magazine.

The unit of analysis was a feature story. A feature story is a nonfiction story that intends to inform or amuse the reader through standard articles, interviews, quotes, sidebars, fillers, or question and answer pieces (Q\&A). To qualify as a feature story, a nonfiction story had to be presented as one semantic unit; indicated by content, colors, a frame around the story, and separate headlines. A total of 753 US and 1743 Dutch feature stories were included in the sample. The number of stories differed because of different publication schemes.

All feature stories were analyzed for whether they explicitly mentioned or made references to sex (e.g., masturbation; oral, anal and/or vaginal sex) or sexual activities (e.g., "we did it," "it happened"). Of the 753 US feature stories, $162(21.5 \%)$ stories were sex-related. Of the 1743 Dutch feature stories, 465 (26.7\%) stories were sexrelated. The greater absolute number of sex-related stories in the Dutch coverage versus the US coverage results from more feature stories in the Dutch magazines.

\section{Procedure}

The codebook used for this study consisted of new items because existing scales either did not exist or were not suitable for our purposes. Most of the items were tested in a pilot study (Joshi et al. 2010), and elicited good validity and inter-coder reliability. The full codebook can be obtained upon request from the first author. To make sure the items and answer categories were culturally relevant and applicable to both US and Dutch magazines, all items in the codebook were pre-tested with a subsample of articles from the US and Dutch magazines. Pre-testing was completed by the principle investigator, a native American-English speaker, and a research assistant, a native Dutch speaker.
Three native American-English speakers served as coders for the US teen magazines, and five native Dutch speakers served as coders for the Dutch teen magazines. We only accepted native speakers as coders because the idiosyncratic meanings attached to sex in each language may be difficult for non-native speakers to identify and understand. The coders were trained by the principle investigator and research assistant. Before coder training started, the coder trainers did an inter-trainer reliability test. This step is crucial in cross-national comparative content analyses to preclude artifacts in the coding as a result of the trainers' idiosyncratic understanding of the codebook (Peter and Lauf 2002). The inter-trainer reliability test showed very high agreement between the trainers. The average inter-trainer reliability for the codebook was $95.2 \%$ $($ Cohen's Kappa $=.87)$.

Coder training took place separately for each country team, and occurred over the course of 2 days. All categories of the codebook were explained and exemplified with five magazine articles. After the training was completed, coders were asked to code five additional articles alone at home. The results were checked by the trainers to see whether the coders sufficiently understood the codebook, and to clarify potential misunderstandings of the categories. Subsequently, an inter-coder reliability test was conducted, separately for the US and Dutch groups, with seven randomly sampled stories from the US or the Dutch magazines. To make sure that the coders' understanding had not changed during the course of the coding, we conducted an intra-coder reliability test 4 weeks after the inter-coder reliability test. In that test, the coders had to code the same stories used in the inter-coder reliability test. The specific inter-coder and intra-coder reliabilities are reported below.

\section{Desire}

For the investigation of sexual desire, the girls and/or boys in the stories had to be depicted as sexual beings. In line with our conceptual definition, sexual desire was operationalized with two indicators: sexual wanting and pleasure. We operationalized sexual wanting by assessing whether the boy and girl in the story were depicted as having their own sexual wishes. We asked, separately for boys and girls, "Is/are the boy(s)/girl(s) in the story depicted as sexual beings (e.g., a person who has or thinks about sex) who have their own sexual desires or wants (e.g., sexual appetite, sexual urges, an expressed sexual wish)?" Categories included "yes," "no," and "not mentioned." Because the focus of this study was on the presence of sexual wanting for boys and girls, we collapsed the latter two categories into one category for the statistical analysis. The average inter-coder reliability for girls' sexual wanting was 91.8\% (Cohen's Kappa=.85) for the American group, and 
$89.0 \%$ (Cohen's Kappa=.81) for the Dutch group. For girls' sexual wanting, the average intra-coder reliabilities were 91.7\% (Cohen's Kappa $=.85$ ) for both the American and Dutch groups. The average inter-coder reliability for boys' sexual wanting was $91.8 \%$ (Cohen's Kappa $=.85$ ) for the American group, and $89.0 \%$ (Cohen's Kappa $=.81$ ) for the Dutch group. For boys' sexual wanting, the average intracoder reliability was $91.7 \%$ (Cohen's Kappa $=.85$ ) for the American group and $81.2 \%$ (Cohen's Kappa $=.75$ ) for the Dutch group.

We operationalized pleasure by assessing whether sex was depicted as a pleasurable activity. More specifically, sexual pleasure referred to sex being depicted as something delightful, pleasant, enjoyable, and/or one or more partners in the story enjoying the act of giving or receiving sexual pleasure. The depiction of sex as pleasurable was assessed separately for girls and boys in the story. Categories included "yes," "no," and "not mentioned." Because we were interested in the presence of sexual pleasure for boys and girls, we combined "no" and "not mentioned" into one category for the statistical analysis. The average inter-coder reliabilities for girls' pleasure were 100\% (Cohen's Kappa= 1.0) for both the American and Dutch groups. For girls' pleasure, the average intra-coder reliability was $100 \%$ (Cohen's Kappa =1.0) for the American group, and 91.7\% (Cohen's kappa $=.85$ ) for the Dutch group. The average inter-coder reliability for boys' pleasure was $91.8 \%$ $($ Cohen's Kappa $=.85$ ) for the American group, and 100\% (Cohen's Kappa =1.0) for the Dutch group. For boys' pleasure, the average intra-coder reliability was $90.3 \%$ (Cohen's Kappa $=.83$ ) for the American group, and 100\% $($ Cohen's Kappa $=1.0)$ for the Dutch group.

\section{Danger}

Sexual danger was operationalized with two indicators: sexual risk and negative physical/health consequences of sex. We measured sexual risk by assessing whether sex was depicted as something dangerous (e.g., sexual abuse, rape, men's aggression), dirty (e.g., if a person has sex he/she are no longer "pure"), and/or disease-ridden (e.g., if a person has sex he/she is likely to contract STDs). Categories to choose from were, "sex is dirty, dangerous, and/or diseaseridden for...": "only boy(s)," "only girl(s)," "both boy(s) and girl(s)," and "no one/not mentioned." For the purpose of our analysis, we recoded the categories, separately for boys and girls, into "sex is a risk," and "sex is not a risk/not mentioned." The average inter- and intra-coder reliabilities for sexual risk, for girls and boys, for the American and Dutch groups were 100\% (Cohen's Kappa=1.0).

We operationalized the negative physical/health consequences of sex by coding whether the stories referred to any harmful outcomes during or after intercourse (e.g., feeling bodily pain or unwell during or after sex, unwanted pregnancy). This was assessed separately for girls and boys. Categories to choose from were "positive," "negative," "both positive and negative," and "not mentioned." Because the focus was on negative physical/health consequences of sex, we recoded the categories into "exclusively negative" and "not exclusively negative/not mentioned" for the statistical analysis. The average interand intra-coder reliabilities for negative physical/health consequences of sex, for girls and boys, for the American and Dutch groups were 100\% (Cohen's Kappa $=1.0$ ).

\section{Data Analysis}

Two characteristics of our data affected the statistical analysis. First, all of our dependent variables were dummy variables. Second, in our coding, country (US vs. Netherlands) was a between-subjects factor (i.e., assessed between stories) and gender was a within-subjects factor (i.e., assessed within a story). This particularly complicated the analysis of the interaction effects between country and gender predicted in $\mathrm{H} 3 \mathrm{a}$ and $\mathrm{H} 3 \mathrm{~b}$. Logistic regression can accommodate both the dummy character of the dependent variables and, when estimated with robust standard errors, the different levels of analysis and thus the nested structure of our variables. However, logistic regression does not lend itself to an easy understanding of our results. General linear models (GLMs), in contrast, can be more intuitively understood, especially in our case where the means of our dummy variables (coded 0 and 1) can be interpreted as proportions (and percentages when multiplied by 100). However, dummy dependent variables may violate some assumptions of GLMs.

Because we wanted to analyze our data most rigorously without sacrificing presentational accessibility, we decided to analyze our data with both GLMs and logistic regressions (with robust standard errors). We present the mean scores that resulted from the GLMs in Tables 1, 2, and 3. The relevant coefficients of the logistic regressions, along with the robust standard errors and odds ratios, are reported in the text. In the case where the results of the logistic regression and the GLM deviated (which occurred only once), we relied on the findings from the logistic regression because it accounts for dummy dependent variables more adequately than a GLM.

\section{Results}

Descriptive Results

Table 1 shows the gender differences for the indicators of sexual desire (i.e., sexual wanting, and pleasure) and danger 
Table 1 Gender differences for sexual desire and danger

\begin{tabular}{lll}
\hline & $\begin{array}{l}\text { Boys } \\
M(S D) \\
(N)\end{array}$ & $\begin{array}{l}\text { Girls } \\
M(S D) \\
(N)\end{array}$ \\
\hline $\begin{array}{l}\text { Sexual Desire } \\
\text { Sexual wanting }\end{array}$ & $.46(.50)_{\mathrm{a}}$ & $.40(.49)_{\mathrm{b}}$ \\
& $(N=627)$ & $(N=627)$ \\
Pleasure & $.21(.38)$ & $.21(.36)$ \\
& $(N=627)$ & $(N=627)$ \\
Sexual Danger & & \\
Sexual risk & $.09(.29)_{\mathrm{a}}$ & $.33(.47)_{\mathrm{b}}$ \\
& $(N=627)$ & $(N=627)$ \\
Negative physical/health consequences & $.07(.26)_{\mathrm{a}}$ & $.31(.46)_{\mathrm{b}}$ \\
of sex & $(N=626)$ & $(N=626)$ \\
\hline
\end{tabular}

Mean values are between 0 and 1 . Significant differences at a level of $p<.001$ are indicated by different subscripts

(i.e., sexual risk, and negative physical/health consequences). Forty-six percent of all stories (i.e., Dutch and US stories combined) depicted sexual wanting for boys and $40 \%$ depicted it for girls. Twenty-one percent of the stories depicted pleasure for girls and boys. Nine percent of the stories portrayed sexual risk for boys and $33 \%$ of the stories depicted it for girls. For the negative physical/health consequences of sex, $7 \%$ of the stories included negative consequences for boys and $31 \%$ of the stories included them for girls.

Table 2 indicates the country differences for the indicators of sexual desire and danger. Fifty-eight percent of the US stories and $38 \%$ of the Dutch stories included sexual wanting. Ten percent of the US stories and $25 \%$ of

Table 2 Country differences for sexual desire and danger

\begin{tabular}{lll}
\hline & $\begin{array}{l}\text { US } \\
M(S D) \\
(N)\end{array}$ & $\begin{array}{l}\text { Dutch } \\
M(S D) \\
(N)\end{array}$ \\
\hline $\begin{array}{lll}\text { Sexual Desire } \\
\text { Sexual wanting }\end{array}$ & $.58(.37)_{\mathrm{a}}$ & $.38(.35)_{\mathrm{b}}$ \\
& $(N=162)$ & $(N=465)$ \\
Pleasure & $.10(.25)_{\mathrm{a}}$ & $.25(.32)_{\mathrm{b}}$ \\
& $(N=162)$ & $(N=465)$ \\
Sexual Danger & & \\
Sexual risk & $.32(.33)_{\mathrm{a}}$ & $.18(.28)_{\mathrm{b}}$ \\
& $(N=162)$ & $(N=465)$ \\
Negative physical/health consequences & $.25(.32)_{\mathrm{a}}$ & $.17(.27)_{\mathrm{b}}$ \\
of sex & $(N=161)$ & $(N=465)$ \\
& & \\
\hline
\end{tabular}

Mean values are between 0 and 1 . Significant differences at a level of $p<.01$ are indicated by different subscripts
Table 3 Gender differences by country for sexual desire and danger

\begin{tabular}{|c|c|c|c|c|}
\hline & \multicolumn{2}{|l|}{ US } & \multicolumn{2}{|l|}{ Dutch } \\
\hline & $\begin{array}{l}\text { Boys } \\
M(S D) \\
(N)\end{array}$ & $\begin{array}{l}\text { Girls } \\
M(S D) \\
(N)\end{array}$ & $\begin{array}{l}\text { Boys } \\
M(S D) \\
(N)\end{array}$ & $\begin{array}{l}\text { Girls } \\
M(S D) \\
(N)\end{array}$ \\
\hline \multicolumn{5}{|l|}{ Sexual Desire } \\
\hline Sexual wanting & $\begin{array}{l}.70(.46) \\
(N=162)\end{array}$ & $\begin{array}{l}.46(.50) \\
(N=162)\end{array}$ & $\begin{array}{l}.38(.49) \\
(N=465)\end{array}$ & $\begin{array}{l}.38(.48) \\
(N=465)\end{array}$ \\
\hline Pleasure & $\begin{array}{l}.12(.33) \\
(N=162)\end{array}$ & $\begin{array}{l}.09(.28) \\
(N=162)\end{array}$ & $\begin{array}{l}.24(.43) \\
(N=465)\end{array}$ & $\begin{array}{l}.26(.44) \\
(N=465)\end{array}$ \\
\hline \multicolumn{5}{|l|}{ Sexual Danger } \\
\hline Sexual risk & $\begin{array}{l}.15(.36) \\
(N=162)\end{array}$ & $\begin{array}{l}.48(.50) \\
(N=162)\end{array}$ & $\begin{array}{l}.07(.26) \\
(N=465)\end{array}$ & $\begin{array}{l}.28(.45) \\
(N=465)\end{array}$ \\
\hline $\begin{array}{l}\text { Negative physical/ } \\
\text { health consequences } \\
\text { of } \operatorname{sex}\end{array}$ & $\begin{array}{l}.11(.31) \\
(N=161)\end{array}$ & $\begin{array}{l}.40(.49) \\
(N=161)\end{array}$ & $\begin{array}{l}.06(.24) \\
(N=465)\end{array}$ & $\begin{array}{l}.28(.45) \\
(N=465)\end{array}$ \\
\hline
\end{tabular}

Mean values are between 0 and 1 . The interaction effect between gender and country for sexual wanting is significant at $p<.01$

the Dutch stories dealt with pleasure. Thirty-two percent of the US stories and $18 \%$ of the Dutch stories involved some kind of sexual risk. Lastly, the negative physical/health consequences of sex were depicted in $25 \%$ of the US stories and in $17 \%$ of the Dutch stories.

\section{Gender Differences}

Hypothesis 1a stated that sexual desire (i.e., sexual wanting, and pleasure) would be portrayed more often for boys than for girls in the teen girl magazines. We conducted one GLM and logistic regression for sexual wanting, and another separate GLM and logistic regression for sexual pleasure. The GLM for sexual wanting revealed a main effect for gender, $F(1,625)=15.36, p<.001$, which was confirmed in the logistic regression $(B=-.25, S E=.11$, Odds Ratio $[\mathrm{OR}]=.78$, $p<.001$; boys coded 0 ). Overall, more stories portrayed sexual wanting for boys than for girls (for descriptives, see Table 1). The GLM for sexual pleasure revealed no main effect for gender, $F(1,625)=.14, n s$, and is in line with the logistic regression $(B=.03, S E=.13, O R=1.03, n s)$. The mean of the stories depicting sexual pleasure for boys was not significantly different from that for girls. Thus, Hypothesis 1a was supported for sexual wanting, but not for sexual pleasure.

Hypothesis $1 \mathrm{~b}$ posed that sexual danger (i.e., sexual risk, and negative physical/health consequences of sex) would be depicted more often for girls than for boys. The GLM for sexual risk revealed a main effect for gender, $F(1,625)=$ $138.38, p<.001$, which was confirmed by the logistic regression $(B=1.62, S E=.15, O R=5.01, p<.001)$. Overall, more stories portrayed sexual risk for girls than for boys. The GLM for negative physical/health consequences of sex also 
revealed a main effect for gender, $F(1,624)=136.88$, $p<.001$, which was supported by the logistic regression $(B=1.79, S E=.18, O R=6.01, p<.001)$. More stories portrayed negative physical/health consequences of sex for girls than for boys. Therefore, Hypothesis $1 \mathrm{~b}$ was supported both for sexual risk and the negative physical/health consequences of sex.

\section{Country Differences}

Hypothesis 2a posited that sexual desire (i.e., sexual wanting, and pleasure) would be portrayed more often in the Dutch teen magazines than in the US teen magazines. We conducted one GLM for sexual wanting and another GLM for sexual pleasure (for descriptives, see Table 2), along with the pertinent logistic regression analyses. The GLM for sexual wanting demonstrated a main effect for country, $F(1,625)=36.56, p<.001$. The main effect suggested that sexual wanting occurred more often in the US stories than in the Dutch stories, and was confirmed in the logistic regression analysis $(B=-.81, S E=.14, O R=.44$, $p<.001$, US coded 0 ). The GLM for sexual pleasure also demonstrated a main effect for country, $F(1,625)=25.73$, $p<.001$, which was supported in the logistic regression $(B=1.02, S E=.22, O R=2.79, p<.001)$. Overall, sexual pleasure occurred more often in the Dutch stories than in the US stories. Therefore, Hypothesis 2a was not supported for sexual wanting, but it was supported for sexual pleasure.

Hypothesis $2 b$ stated that sexual danger (i.e., sexual risk, and negative physical/health consequences of sex) would be depicted more often in the US teen magazines than in the Dutch coverage. In line with the logistic regression analysis $(B=-.85, S E=.17, O R=.43, p<.001)$, the GLM for sexual risk demonstrated a main effect for country, $F(1,625)=26.75, p<.001$. Sexual risk occurred more often in the US stories than in the Dutch stories. The GLM for the negative physical/health consequences of sex also showed a main effect for country, $F(1,624)=10.13$, $p<.01$, which was confirmed by the logistic regression analysis $(B=-.55, S E=.16, O R=.58, p<.001)$. The negative physical/health consequences of sex occurred more often in the US stories than in the Dutch stories. Thus, Hypothesis $2 \mathrm{~b}$ was supported both for sexual risk and the negative physical/health consequences of sex.

\section{Gender Differences by Country}

Hypothesis $3 \mathrm{a}$ asserted that there would be a greater gender difference for sexual desire (i.e., sexual wanting, and pleasure) in the US magazines than the Dutch magazines. Both for sexual wanting and for sexual pleasure, one GLM and one logistic regression were conducted. The means that were tested in the GLMs can be found in Table 3. The GLM for sexual wanting showed a significant interaction effect between gender and country, $F(1,625)=15.93$, $p<.001$, which was in line with the findings of the logistic regression analysis $(B=.99, S E=.25, O R=2.70, p<.001)$. This interaction effect qualified the aforementioned main effects found for sexual wanting and indicated two things. First, the difference between boys' and girls' sexual wanting only occurred in the US coverage, $t(161)=4.93$, $p<.001$ but not in the Dutch coverage, $t(464)=-.07$, ns. Second, the higher percentages of sexual wanting in the US coverage (i.e., the main effect for country) was largely due to the high scores of sexual wanting for US boys. Neither the logistic regression $(B=.50, S E=.34, O R=1.65, n s)$ nor the GLM for sexual pleasure, $F(1,625)=1.38, n s$, showed a significant interaction effect between gender and country. Thus, for sexual pleasure, the difference between boys' and girls' sexual pleasure in the US coverage did not differ from that in the Dutch coverage. In conclusion, Hypothesis $3 \mathrm{a}$ was supported for sexual wanting but not for sexual pleasure.

Hypothesis $3 b$ stated that there would be a greater gender difference for sexual danger (i.e., sexual risk, and negative physical/health consequences of sex) in the US magazines than the Dutch magazines. The GLM for sexual risk showed a significant interaction effect between gender and country, $F(1,625)=6.48, p<.05$. However, this interaction effect was not significant in the logistic regression analysis, $(B=-.01, S E=.31, O R=1.01, n s)$. Thus, we concluded that gender differences in the portrayal of sexual risk did not vary between the US and the Dutch magazines. For the second indicator, negative physical/ health consequences of sex, neither the logistic regression $(B=.09, S E=.34, O R=1.09, n s)$ nor the GLM, $F(1,624)=$ $2.79, n s$, showed a significant interaction effect between gender and country. This lack of an interaction effect indicates that the difference between boys and girls in the US coverage was not significantly different from that in the Dutch coverage. In conclusion, Hypothesis $3 \mathrm{~b}$ was neither supported for sexual risk nor for the negative physical/ health consequences of sex.

\section{Discussion}

This study has extended existing research on sexual desire and danger in adolescent sexuality through a cross-national quantitative content analysis of the depiction of sexual desire and danger in US and Dutch teen girl magazines (e.g., Herzog 2008; Kim and Ward 2004; Tolman 2002). Relying on the sexual scripts framework and Hofstede's (1998a, 2001) cultural dimension of masculinity/femininity, we investigated how the depiction of sexual desire and 
danger differed between girls and boys, as well as between countries. We were also interested in whether potential gender differences for sexual desire and danger varied between countries.

\section{Gender Differences}

In line with previous research on the Heterosexual Script, distinct differences emerged in how boys' and girls' sexual wanting was covered, but these differences varied by country. Sexual wanting occurred more often for boys than for girls in the US coverage, whereas no gender difference emerged in the Dutch coverage. Thus, similar to earlier US-based research (e.g., Lerum and Dworkin 2009; Tolman 2002), our study also found traditional notions of adolescent sexuality in the coverage of contemporary US teen girl magazines. While girls were not depicted as being asexual, boys' sexual wanting was still the main focus of the US coverage. In line with what Fine (1988) revealed almost 20 years ago, a missing discourse of desire for girls still lingers, and is present in today's US teen girl magazines.

In contrast to what previous research suggests (Kim and Ward 2004; Tolman 2002), no gender difference emerged for the depiction of sexual pleasure. Boys' and girls' sexual pleasure received approximately the same amount of coverage. This finding suggests a more genderegalitarian tendency in the coverage of pleasure. It seems that the Heterosexual Script, as reflected in the teen girl magazine coverage we investigated, may be evolving to include girls' sexual pleasure rather than focusing solely on boys' pleasure. Thus, while our findings for sexual wanting confirm Fine's (1988) missing discourse of desire, our findings concerning pleasure do not. This unexpected finding awaits replication in other contexts to be tested for its robustness. That said, our finding suggests that it may be worth conceptualizing desire by taking into account various dimensions of desire, such as wanting and pleasure.

Sexual danger, both in terms of sexual risks and the negative physical/health consequences of sex, occurred more often for girls than for boys. Overall, our findings mirror previous research on the danger discourse of women's sexuality (Kim et al. 2007; Stankiewicz and Rosselli 2008). Specifically, this finding fits the traditional notions of gender mentioned earlier, where boys in contrast to girls enjoy sex without risks and negative consequences (Farvid and Braun 2006; Hyde and Oliver 1993). However, it is also possible that the focus on girls' sexual danger emerged because the coverage of teen girl magazines is geared towards a girl readership. Thus, a selection bias inherent to our sample may explain why sexual danger is emphasized more for girls than for boys.

\section{Country Differences}

In contrast to predictions derived from Hofstede's (1998a, b, 2001) cultural dimension of masculinity/ femininity, sexual wanting occurred more often in the US magazines than in the Dutch magazines. There are two possible explanations for this unexpected finding. First, as Schalet (2000) points out, sex in the Netherlands is strongly associated with love and is rarely stigmatized. In contrast, the stigmatization of sex in the US (Schalet 2000) may turn sex more into a forbidden fruit, especially for US teenagers. Consequently, the appeal of sex may be higher for US adolescents than for Dutch adolescents, and this is reflected in the teen magazine coverage of sexual wanting. A second explanation for the unexpected country difference is that sexual wanting is linked with the notion of sex as a competitive achievement (Hofstede 1998b). According to that notion, sexual wanting is associated with winning an ego-boosting contest rather than establishing a relationship. Hofstede (1998b) considers the achievement orientation toward sex as more typical of masculine societies, such as the US, than of feminine societies, such as the Netherlands.

Coinciding with Hofstede's (1998b) notions of a feminine society, the Dutch magazines focused more often on sexual pleasure than the US magazines. It is typical of a feminine society that parents and teenagers feel that sex is something to be enjoyed (Schalet 2000, 2004). Our results show that this emphasis on the pleasure of sex also applies to the coverage of teen girl magazines and adolescent sexuality. To our knowledge, Hofstede's cultural dimension of masculinity has hardly been applied in research on media and adolescents' sexual socialization. Our results seem to be a promising starting point for more cross-national comparative research on the issue. However, it is important to note that masculinity/femininity is a country-level concept that is not able to detect and explain withincountry differences and individual behavior. Both the US and Netherlands contain regions and groups of people that may not fit the country-level classification of a masculine or feminine society, and our results should not be used for stereotypical simplifications of these two countries.

In terms of sexual danger, the focus of US magazines on the risks and consequences of sex reflected differences between masculine and feminine societies. Specifically, this focus mirrors the predominant message delivered to teenagers in many US schools, namely that the safest kind of sex is to not have sex at all (Luker 2006). Thus, the US coverage partly subscribes to the underlying assumptions of abstinence-only programs by creating a danger discourse that surrounds adolescent sexuality, while the Dutch coverage reflects the more positive approach to adolescent sexuality in the Netherlands. 
Overall, the coverage of sexual wanting, sexual risk, and the negative consequences of sex occurred more often in the US than in the Netherlands. Specifically, US adolescents were more frequently portrayed as having distinct sexual wants, but simultaneously they were more often cautioned about the risks and consequences of sex than Dutch adolescents. Our comparative analysis thus extends Tolman's (2002) finding on ambivalence in US adolescent girls' sexuality. Compared to the Netherlands, US teen girl magazines seem to contain more sexually ambivalent messages - that is, mixed messages about sex and sexuality - for both boys and girls, albeit to varying degrees.

Although our comparative analysis points to country differences in the coverage of teen girl magazines, we should emphasize that these findings may be related to certain peculiarities of the magazines. Teen girl magazines are typically made for a national market with a clearly defined target group. Consequently, country differences may be less surprising for teen girl magazines than for other media, such as television or the internet. As a matter of fact, (sexual) content on television or the internet is likely to be similar between the US and the Netherlands, largely due to an extensive flow of US-produced material to the Netherlands (Ter Bogt et al. 2010). Moreover, internet pornography, a globalized sexual genre, seems to affect US and Dutch adolescents similarly (Brown and L'Engle 2009; Peter and Valkenburg 2010). For a better understanding of country differences and similarities, it is essential to pay more attention to sexual content in media other than teen girl magazines.

\section{Gender Differences by Country}

Our comparative perspective also enabled us to analyze how gender differences in the depiction of desire and danger varied between the US and Dutch coverage. For sexual wanting, we found a difference between boys and girls in the coverage of the US magazines but not in that of the Dutch magazines. These country-dependent gender differences illustrate that the US-based Heterosexual Script, as any cultural script, is culturally contingent. However, because existing research has been exclusively singlecountry research, this important property of the Heterosexual Script has not yet been documented. The Heterosexual Script has been developed mainly in US research (e.g., Kim et al. 2007; Tolman 2002) and has hardly been applied to non-US research. Our findings suggest that, in the coverage of sexual wanting in teen girl magazines, heterosexuality is constructed differently in the Netherlands than in the US. Our country-dependent gender differences in the coverage of sexual wanting are also in line with Hofstede's (1998a, b) concept of feminine societies in which gender differences are generally less distinct than in masculine societies.
Thus, more comparative research on this gender difference may not only help us further develop the Heterosexual Script concept, but may allow us to better understand the cultural contingency of adolescent sexual socialization.

Simultaneously, however, it is remarkable that gender differences in the coverage of pleasure and sexual danger, in particular, did not vary between the two countries. Dutch magazines generally portrayed pleasure more often, and danger less often, than US magazines. Still, in both countries, gender differences were either absent, as for pleasure, or followed traditional lines, as for sexual danger. The finding that, in both countries, pleasure was depicted as often for boys as for girls could be attributed to US gender roles shifting towards more gender equality (Bolzendahl and Myers 2004; Risman and Schwartz 2002). In addition, the similar gender differences in the US and Dutch coverage of sexual danger puts an interesting spin on the construction of adolescent sexuality in the US and the Netherlands. Teen girl magazines in feminine societies such as the Netherlands seem to attribute positive aspects of adolescent sexuality, such as sexual desire, equally to boys and girls. However, when it comes to the negative aspects of adolescent sexuality, girls seem to be much more affected than boys, in the magazine coverage of both feminine and masculine societies. This gender difference is very much in line with the Heterosexual Script. Thus, the Heterosexual Script and the gender differences it entails seem to depend on the cultural dimension of masculinity/ femininity only for the positive aspects of sexuality, but not for the negative aspects.

This research was supported by a grant from the Netherlands Organisation for Scientific Research (NWO) awarded to the second and third author. The authors would like to thank Marleen Klaassen for her help during data collection.

Open Access This article is distributed under the terms of the Creative Commons Attribution Noncommercial License which permits any noncommercial use, distribution, and reproduction in any medium, provided the original author(s) and source are credited.

\section{References}

American Psychological Association, Task Force on the Sexualization of Girls. (2007). Report of the APA Task Force on the Sexualization of Girls. Washington, DC: American Psychological Association. Retrieved from http://www.apa.org/pi/wpo/sexualization.html.

Bolzendahl, C., \& Myers, D. J. (2004). Feminist attitudes and support for gender equality: Opinion change in women and men, 19741998. Social Forces, 83, 759-790. doi:10.1353/sof.2005.0005.

Bowleg, L., Lucas, K. J., \& Tschann, J. M. (2004). "The ball was always in his court": An exploratory analysis of relationship scripts, sexual scripts, and condom use among African American women. Psychology of Women Quarterly, 28, 70-82. doi:10.1111/j.1471-6402.2004.00124.x. 
Brown, J. D., \& L'Engle, K. L. (2009). X-Rated: Sexual attitudes and behaviors associated with U.S. early adolescents' exposure to sexually explicit media. Communication Research, 36, 129-151. doi:10.1177/0093650208326465.

Brown, J. D., L'Engle, K. L., Pardun, C. J., Guo, G., Kenneavy, K., \& Jackson, C. (2006). Sexy media matter: Exposure to sexual content in music, movies, television, and magazines predicts black and white adolescents' sexual behavior. Pediatrics, 117, 1018-1027. doi:10.1542/peds.2005-1406.

Carpenter, L. M. (1998). From girls into women: Scripts for sexuality and romance in Seventeen magazine, 1974-1994. Journal of Sex Research, 35, 158-168.

Carpenter, L. M. (2001). The First Time/Das Erstes Mal: Approaches to virginity loss in U.S. and German teen magazines. Youth \& Society, 33, 31-61. doi:10.1177/0044118X01033001002.

Clarke, R. D., \& Hatfield, E. (1989). Gender differences in receptivity to sexual offers. Journal of Psychology \& Human Sexuality, 2, 39-55.

de Graaf, H., Meijer, S., Poelman, J., \& Vanwesenbeeck, I. (2005). Seks onder je $25^{\text {ste }}$ (Sex among people younger than 25). Utrecht/ Amsterdam: Rutgers Nisso Group.

Diamond, L. (2005). "I'm straight but I kissed a girl": The trouble with American media representations of female-female sexuality. Feminism \& Psychology, 15, 104-110. doi:10.1177/0959353505049712 .

Durham, M. (1998). Dilemmas of desire: Representations of adolescent sexuality in two teen magazines. Youth \& Society, 29, 369389. doi:10.1177/0044118X98029003005.

Epstein, M., \& Ward, L. M. (2008). "Always use protection": Communication boys receive about sex from parents, peers, and the media. Journal of Youth \& Adolescence, 37, 113-126. doi:10.1007/s10964-007-9187-1.

Farvid, P., \& Braun, V. (2006). 'Most of us guys are raring to go anytime, anyplace, anywhere': Male and female sexuality in Cleo and Cosmo. Sex Roles, 55, 295-310. doi:10.1007/s11199-006-9084-1.

Fine, M. (1988). Sexuality, schooling, and adolescent females: The missing discourse of desire. Harvard Educational Review, 58, 29-53.

Firminger, K. B. (2006). Is he boyfriend material? Representation of males in teenage girls' magazines. Men and Masculinities, 8, 298-308. doi:10.1177/1097184X05282074.

Ford, C. S., \& Beach, F. A. (1951). Patterns of sexual behavior. New York: Harper \& Brothers.

Frayser, S. G. (1985). Varieties of sexual experience: An anthropological perspective on human sexuality. New Haven: Human Relations Area Files Press.

Garner, A., Sterk, H. M., \& Adams, S. (1998). Narrative analysis of sexual etiquette in teenage magazines. The Journal of Communication, 48, 59-78. doi:10.1111/j.1460-2466.1998.tb02770.x.

Gregersen, E. (1986). Human sexuality in cross-cultural perspective. In D. Byrne \& K. Kelly (Eds.), Alternative approaches to the study of sexual behavior (pp. 87-102). Hillsdale: Erlbaum.

Herzog, D. (2008). Sex in crisis: The new sexual revolution and the future of American politics. New York: Basic Books.

Hofstede, G. (1998a). Masculinity/Femininity as a dimension of culture. In G. Hofstede, and Associates (Ed.), Masculinity and femininity: The taboo dimensions of national cultures, (pp. 328). Thousand Oaks, CA: Sage.

Hofstede, G. (1998b). Comparative studies of sexual behavior: Sex as achievement or as relationship? In G. Hofstede and associates (Eds.), Masculinity and femininity: The taboo dimensions of national cultures, (pp. 153-178). Thousand Oaks, CA: Sage.

Hofstede, G. (2001). Culture's consequences. Comparing values, behaviors, institutions, and organizations across nations (2nd ed.). Thousand Oaks, CA: Sage.

Hollway, W. (1989). Subjectivity and method in psychology: Gender, meaning and science. London: Sage.
Hust, S. J. T., Brown, J. D., \& L’Engle, K. L. (2008). Boys will be boys and girls better be prepared: An analysis of the rare sexual health messages in young adolescents' media. Mass Communication and Society, 11, 3-23. doi:10.1080/15205430701668139.

Hyde, J. S., \& Oliver, M. B. (1993). Gender differences in sexuality: Results from meta-analysis. Psychological Bulletin, $114,29-51$.

Hynie, M., Lydon, J. E., Coté, S., \& Wiener, S. (1998). Relational sexual scripts and women's condom use: The importance of internalized norms. Journal of Sex Research, 35, 370-380.

Johnson, M. A., Gotthoffer, A. R., \& Lauffer, K. A. (1999). The sexual and reproductive content of African American and Latino magazines. Howard Journal of Communications, 10, 169-187. doi:1064-6175/99.

Joshi, S. P., Peter, J., \& Valkenburg, P. M. (2010). Ambivalent messages in Seventeen magazine: A content analytic comparison of 1997 and 2007. Journal of Magazine and New Media Research.

Kilmartin, C. T. (1999). Pleasure and performance: Male sexuality. In K. Lebacqz \& D. Sinacore-Guinn (Eds.), Sexuality: A reader (pp. 179-186). Cleveland: Pilgrim.

Kim, J. L., \& Ward, L. M. (2004). Pleasure reading: Associations between young women's sexual attitudes and their reading of contemporary women's magazines. Psychology of Women Quarterly, 28, 45-58. doi:10.1111/j.1471-6402.2004.00122.x.

Kim, J. L., Sorsoli, C. L., Collins, K., Zylbergold, B. A., Schooler, D., \& Tolman, D. L. (2007). From sex to sexuality: Exposing the Heterosexual Script on primetime network television. Journal of Sex Research, 44, 145-157. doi:10.1080/00224490701263660.

Kunkel, D., Eyal, K., Finnerty, K., Biely, E., \& Donnerstein, E. (2005). Sex on TV 4. Menlo Park: Kaiser Family Foundation.

Laumann, E. O., Gagnon, J. H., Michael, R. T., \& Michaels, S. (1994). The social organization of sexuality: Sexual practices in the United States. Chicago: University of Chicago Press.

Lerum, K., \& Dworkin, S. L. (2009). "Bad girls rule": An interdisciplinary feminist commentary on the report of the APA Task Force on the sexualization of girls. Journal of Sex Research, 46, 250-263. doi:10.1080/00224490903079542.

Luker, K. (2006). When sex goes to school: Warring views on sexand sex education - since the Sixties. New York: W. W. Norton.

Mackie, T., \& Marsh, D. (1995). The comparative method. In D. Marsh \& G. Stoker (Eds.), Theory and methods in political science (pp. 173-188). New York: St. Martin's Press.

Martin, K. A. (1996). Puberty, sexuality, and the self: Girls and boys at adolescence. New York: Routledge.

McCormick, N. B. (1979). Come-ons and put-offs. Unmarried students' strategies for having and avoiding sexual intercourse. Psychology of Women Quarterly, 4, 194-211. doi:10.1111/ j.1471-6402.1979.tb00708.x.

McCormick, N. B., Brannigan, G. G., \& LaPlante, M. N. (1984). Social desirability in the bedroom: Role of approval motivation in sexual relationships. Sex Roles, 11, 303-314. doi:10.1007/ BF00287522.

Peter, J., \& Lauf, E. (2002). Reliability in cross-national content analysis. Journalism \& Mass Communication Quarterly, 79, 815-832.

Peter, J., \& Valkenburg, P. M. (2007). Adolescents' exposure to a sexualized media environment and their notions of women as sex objects. Sex Roles, 56, 381-395. doi:10.1007/s11199-006-9176-y.

Peter, J., \& Valkenburg, P. M. (2010). Processes underlying the effects of adolescents' use of sexually explicit internet material: The role of perceived realism. Communication Research, 37, 375-399. doi:10.1177/0093650210362464.

Pinkleton, B. E., Austin, E. W., Cohen, M., Chen, Y., \& Fitzgerald, E. (2008). Effects of a peer-led media literacy curriculum on adolescents' knowledge and attitudes toward sexual behavior and media portrayals of sex. Health Communication, 23, 462472. doi: $10.1080 / 10410230802342135$. 
Prinstein, M. J., Meade, C. S., \& Cohen, G. L. (2003). Adolescent oral sex, peer popularity, and perceptions of best friends' sexual behavior. Journal of Pediatric Psychology, 28, 243-249. doi:10.1093/jpepsy/jsg012.

Risman, B., \& Schwartz, P. (2002). After the sexual revolution: Gender politics in teen dating. Contexts, 1, 16-24. doi:10.1525/ ctx.2002.1.1.16.

Roberts, C., Kippax, S., Waldby, C., \& Crawford, J. (1995). Faking it: The story of “Ohh!". Women's Studies International Forum, 18, 523-532. doi:10.1016/0277-5395(95)00047-X.

Schalet, A. T. (2000). Raging hormones, regulated love: Adolescent sexuality and the constitution of the modern individual in the United States and the Netherlands. Body Society, 6, 75-105. doi:10.1177/1357034X00006001006.

Schalet, A. T. (2004). Must we fear adolescent sexuality? Medscape General Medicine, 6(4).

Schlenker, J. A., Caron, S. L., \& Halteman, W. A. (1998). A feminist analysis of Seventeen Magazine: Content analysis from 1945 to 1995. Sex Roles, 38, 135-149. doi:10.1023/ A:1018720813673.

Simon, W., \& Gagnon, J. H. (1984). Sexual scripts. Society, 22, 5360. doi:10.1007/BF02701260.

Stankiewicz, J. M., \& Rosselli, F. (2008). Women as sex objects and victims in print advertisements. Sex Roles, 58, 579-589. doi:10.1007/s11199-007-9359-1.

Stibbe, A. (2004). Health and the social construction of masculinity in Men's Health magazine. Men and Masculinities, 7, 31-51. doi:10.1177/1097184X03257441.
Taylor, L. D. (2005). All for him: Articles about sex in American Lad magazines. Sex Roles, 52, 153-163. doi:10.1007/s11199-0051291-7.

Ter Bogt, T., Engels, R., Bogers, S., \& Kloosterman, M. (2010). "Shake It Baby, Shake It": Media preferences, sexual attitudes and gender stereotypes among adolescents. Sex Roles, 63, 844859. doi:10.1007/s11199-010-9815-1.

Tolman, D. L. (1994). Doing desire: Adolescent girls' struggles for/ with sexuality. Gender and Society, 8, 324-342. doi:10.1177/ 089124394008003003.

Tolman, D. L. (2000). Object lessons: Romance, violence and female adolescent sexual desire. Journal of Sex Education and Therapy, 25(1), 70-79.

Tolman, D. L. (2002). Dilemmas of Desire: Teenage girls talk about sexuality. Cambridge: Harvard University Press.

Walsh-Childers, K., Gotthoffer, A., \& Lepre, C. R. (2002). From “just the facts" to "downright salacious": Teens and women's magazine coverage of sex and sexual health. In J. D. Brown, J. R. Steele, \& K. Walsh-Childers (Eds.), Sexual teens, sexual media: Investigating media's influence on adolescent sexuality (pp. 153-171). Mahwah: Erlbaum.

Ward, L. M. (2003). Understanding the role of entertainment media in the sexual socialization of American youth: A review of empirical research. Developmental Review, 23, 347-388. doi:10.1016/S0273-2297(03)00013-3.

Willemsen, T. M. (1998). Widening the gender gap: Teenage magazines for girls and boys. Sex Roles, 38, 851-861. doi:10.1023/A:1018881316340. 